\title{
Social Contexts of Trauma and Healing*
}

\author{
DEAN AJDUKOVIC \\ Department of Psychology, University of Zagreb, 10000 Zagreb, Croatia
}

\begin{abstract}
The social contexts in which the mass trauma of thousands of people occur and in which their recovery should progress have qualities that distinguish it in important ways from individualised trauma in which a person is a victim of a violent attack, rape or a traffic accident. Organised violence, such as wars, oppression by dictatorships and massive terrorist attacks are extreme cases in which hundreds or thousands of people are exposed to trauma in a short period of time. As such, it has multiple consequences that extend beyond the affected individuals and the symptoms they suffer. Although the symptoms may be similar, the social contexts in which individual victimisation and exposure to organised violence happen are very different. The social milieu in which the survivors of individual trauma and survivors of mass trauma are embedded is likewise different, with important consequences for recovery. Understanding the social context of the trauma helps create the right social intervention for healing at social and personal levels.
\end{abstract}

KEYWORDS Conflict Culture Post traumatic stress disorder Social healing Trauma Yugoslavia

The role of social factors on traumatic experiences is well recognised. ${ }^{1}$ These include the impact of trauma on the community and other factors that may also be socio-contextual such as location of the trauma (home or elsewhere), exposure to social chaos and the level of displacement from the community. The term loss of communality was coined to describe the massive social and individual trauma in the Buffalo Creek Dam disaster in which many socio-cultural support systems necessary for recovery were eliminated. ${ }^{2}$ Others have emphasised the characteristics of the social situation that determine the intensity and content of the symptoms, of coping, and in this sense also the occurrence of post-traumatic stress disorder (PTSD). The focus of these considerations was primarily the extent to which people get support from others. Research has been summarised showing that decline in social support and social embeddedness explained much of the mental health consequences of natural disasters. ${ }^{3}$ It is argued that the time has come to move beyond the

${ }^{*} \mathrm{~A}$ shorter version of this paper was presented at the VIII European Conference on Traumatic Stress (ECOTS), Berlin, May 2003.

MEDICINE, CONFLICT AND SURVIVAL, VOL. 20, NO. 2, 120-135 (2004)

ISSN 1362-3699 print

DOI: $10.1080 / 1362369042000234717$ (C) 2004 Taylor \& Francis Ltd. 
dominating 'dose-response' paradigm and that much more work is needed on family and community processes that foster resilience or impede recovery. In place of the universal use of the term 'psychological trauma' for an enormous range of horrific happenings, terms such as 'social trauma', 'collective trauma' or 'mass trauma', that would better capture most characteristics of repeated and prolonged mass disasters and sustained violence, have been proposed. ${ }^{4}$

\section{Social Context of Mass Trauma}

In the case of individualised victimisation, such as rape, traffic accidents and random shooting, a person is severely affected by the traumatic experience and his or her life can change. This can have major effects on the whole family system and the lives of other family members. Lasting physical incapacity, dysfunctional behaviours, lack of capacity to keep a job or abusive behaviours in the family are only some consequences that build upon the troubling symptoms of a trauma victim. However, if the trauma victim has access to appropriate assistance, support and treatment, he or she stands a good change of getting on with a constructive life as a member of the community.

However, massive violence affects both individuals who have personally suffered trauma and the community in which these events happened. Relatively small communities such as Srebrenica and Mostar in Bosnia or Vukovar in Croatia are but a few among the many that have gone through such experiences in Europe at the end of the twentieth century. Such trauma is not inflicted in social isolation. On the contrary, it is intentional, designed to hurt and destroy people, it is inflicted on selected groups and particular individuals in order to send a symbolic message to other communities. In fact, such violence has a clear instrumental purpose.

The consequences of mass trauma are long-lasting, as in individual trauma, but the support mechanisms are typically far from adequate to meet the needs. At the same time, the search for the meaning of what has happened is extremely difficult. People who have been exposed to such events feel that gross injustice has been done to many of them and that their basic rights as human beings have been violated. They therefore seek trials of the individuals they see as perpetrators of human rights abuses, not only those who have inflicted extreme pain to them and threatened their life. This connects the individual traumatic event with the meaning of collective violence in the societal context.

In addition to having suffered trauma, the affected people have experienced a whole range of losses, such as family, a home, relatives, friends, jobs and professional identity. The communities they knew are fragmented; social networks and other support mechanisms to which they normally turned are shattered. An increase in family violence, child and spouse abuse and public violence is a pattern that is evident in all countries 
affected by upheaval and social transition. Such context and behavioural patterns increase the likelihood of trans-generational transmission of violence.

Once people are able to return to their devastated original communities, the expectation is that they should start functioning normally and look at the hard work of rebuilding their homes and lives as a challenge. In principle, they are expected to put past suffering aside, together with their traumatic experiences and symptoms, and build a better future. This is what they are told by the rest of the population that has not been severely affected, by the authorities, by health workers, and above all by the representatives of the international community.

In such contexts, at the individual level, we tend to screen for symptoms of trauma and look at PTSD as a core concept related to exposure to violence. This is strongly based on the dose-response medical model that has proved adequate if we look for PTSD symptoms alone. The diagnosis of PTSD focuses exclusively on the traumatic event and the subsequent reactions. The social understanding of the violent event does not sufficiently enter into consideration.

At the community level, collective violence disrupts normal patterns of social activities, fractures social relationships, and damages social structures. People feel betrayed, and both value systems and moral norms are disturbed. Disempowerment is not only individual but also collective, adding to the questioning of basic assumptions about the world around.

\section{Processes}

In explaining the processes that shape the social context in which trauma happens due to organised violence, several concepts are helpful, such as 'social breakdown's and 'social capital'.6,7

Functioning of any society is based on social norms of accepted and expected behaviour in certain situations. The norms are reflected in the values of society, so that people know what is right, good and desirable. Taken together, social values constitute an important part of a culture and represent behavioural cornerstones. However, in times of upheaval, social norms are violated seemingly without consequences. In such circumstances, people begin to doubt the fundamental values that they previously upheld. When they confront previously unimaginable traumatising events and suffering, existing value structures may start looking inappropriate. Seeing that others do not abide by the norms and that some individuals achieve goals in previously unacceptable ways, people begin to wonder if they should also change and adjust. Under such circumstances social institutions and relationships no longer function in a familiar way, difficulties that did not exist before now arise in interpersonal relations, people become confused and often frightened, and feel uncertainty. Individuals feel existentially confused, asking themselves: Who am I? Who are my 
neighbours? What is the future like for my family and me? How could my close friends have changed so much?

The next stage is decreased trust in other people, doubt about their intentions, and turning toward one's own group, be it relatives, ethnic, religious, or any other group providing psychological safety. In difficult times our preference grows stronger for contacts with people who belong to our group or that are similar to us. Parallel to this, our relations to people who belong to out-groups decay and the negative attributes assigned to them as a group grow. If leaders support such behaviour, emphasising the need for homogeneity in the group and differences in relation to other groups, the community gradually becomes socially divided and different groups with conflicting interests start perceiving each other as enemies. The communities fall apart.

A functioning community maintains the social relations necessary for meeting individual and common interests. This is enshrined in mutual trust of community members, respect for social norms, acceptance of common values and constructive ways of articulating needs and interests. In such communities, people feel safe, accepted and can rely on one other. Because of the stable relationships among members of such a community, it will abound in a resource called 'social capital'. This concept includes the trust, accepted norms, and the connectedness that increase the community's efficiency because it facilitates collective actions. ${ }^{6,7}$

In societies that eventually collapsed in collective violence, one can recognise the process that lead to loss of mutual trust, disruption of norms and decreasing efficiency, resulting in the quick loss of social capital. Our retrospective study into feelings of trust and betrayal by close neighbours and life-long friends in the city of Vukovar ${ }^{8}$ has clearly identified such a process.

In this study, 61 adults were interviewed about the circumstances, experiences and consequences of separation of close friends from Croat and Serb ethnic backgrounds in the conflict-riven city of Vukovar in 1991, when dreadful atrocities were committed. The increasing feelings of helplessness, fear and lack of full understanding of what was going on were the major factors identified as setting the stage for the break-up of close relationships. The crucial moment that made many of our respondents feel betrayed and break off friendships was the belief that their life-long friends had information about what was going to happen, but failed to share it. Even in retrospect, after 12 years they were convinced that their friends withheld information that could have meant life and death for them and their family and left the city without saying goodbye. Respondents from the other group have never said that they withheld any information from their friends, and often described the dramatic circumstances under which they had urgently left the city.

In multiethnic societies, the differences between the 'in-group' and 'outgroups' that had no significance for societal functioning can suddenly 
become of paramount importance under certain circumstances. When instability evolves in a multiethnic country, ethnic minorities begin to fear that the ethnic majority will use its advantage and turn state institutions into instruments of ethnic dominance, and begin to feel insecure. This leads to the creation of 'a fiction of nationalism'.

Individuals have the feeling that they cannot equally trust their friends and neighbours from a different ethnic group any longer. An illustration is the case of a woman from our study who had been very close friends with a married couple of another nationality for 30 years. As she puts it, 'we were closer than sisters and brothers'. However, in the spring of 1991, she became alarmed that her friends preferred to exclusively watch television programmes aimed at their own ethnic group. She started to doubt the sincerity of their friendship and began to interpret some of their statements as hostile toward her and her ethnic group. The 'fiction of nationalism' introduces fear in communities and motivates closing into groups because of the belief that people's safety depends on their 'sticking together'; because the social institutions become inefficient and the out-group members cannot be trusted any more; 'communities of fear' are formed. The answer to the question 'who will protect me now?' becomes 'my own people'.

It is argued that three vectors are key to turning the minor human differences into major ones: power, fear and guilt. No human difference matters much until it becomes a privilege or the basis for oppression. Guilt has a role because if people from the now dominant group who had shared a common life with another group but suddenly begin to fear them, they project the blame for destroying a common life on to those whom they fear, in order to overcome the weight of happy memories. ${ }^{9}$

A model of social collapse based on the events that took place on the territory of former Yugoslavia has been suggested. ${ }^{10}$ The model holds that there are three phases that lead to social collapse.

In the first phase, certain events lead to economic and political instability and isolated resistance, eventually provoking responses from authorities. This fuels extremism, organised resistance, persecution of non-sympathisers, and nationalism. Further steps are isolated cases of violence and the repression they provoked.

Isolated cases of violence escalate, leading to the second phase of social collapse, which is mass violence and war. In this phase, violence destroys physical, economic, and social infrastructure, leads to displacement, the mass trauma of people and eventually to the collapse of the structures of society. Social norms concede to violence, so that war crimes and violation of human rights become phenomena accompanying social collapse.

The third and final phase of the collapse is the end of armed conflict, usually when the international community becomes actively engaged in reestablishing peace. As disintegration of the community does not happen in a social vacuum but abounds in instrumental violence, the search for meaning as a core of recovery from trauma is extremely difficult. 


\section{The Social Context of Trauma Healing}

Once the politics allow and safety permits, populations can start resettling in their original communities. While doing this, they are confronted with destroyed homes and communities and meeting former adversaries face to face. For traumatised and hurt people who have suffered multiple losses this is a very difficult experience. In addition to their own traumatic experiences, many people have to cope with the fact that they have missing family members, they face unemployment, have very difficult living conditions, insufficient social services and schooling, minefields that are an obstacle to farming, and loss of personal and professional identity. Lack of control over life and lack of opportunity for planning their lives makes people feel disempowered and helpless, in addition to post-traumatic symptoms.

It is clear that the effects of organised violence extend far beyond the traumatic exposure, both in time and psychosocial implications. For many people, this is a critical period because of exposure to traumatic triggers, retraumatising experiences and painful reality testing. Under such conditions, creating a safe and stimulating environment in which people can heal and communities rebuild is an almost impossible task given the ongoing priorities of meeting existential needs, rebuilding the infrastructure and the lack of awareness of mental health needs.

Communities destroyed by violence need a community approach. This sounds like a tautological truism, but in fact it is a more demanding task than it appears. An obstacle to putting it to work includes the prevailing medical model of treating traumatised individuals regardless of the aetiology of trauma, be it a street rape, traffic accidents, a sniper shooting at school children or major surgery. The focus is almost exclusively on PTSD as a syndrome and treating the individual separate from the social milieu in which the recovery should progress.

After organised violence one of the key issues is to reconstruct meaningful environments. In doing this, care-providers should appreciate the integrated, holistic helping approach that considers various levels of the ecology in which the traumatised individual is embedded. As with a family, the community should be empowered to provide a holding context for its traumatised members and groups. However, the key question is whether communities have such a capacity if they themselves are devastated and often divided across ethnic, religious or racial lines.

The task of effective community-based interventions is to facilitate psychosocial reconstruction of the communities, decrease social tensions among groups that have been involved in conflict, provide treatment for the most traumatised individuals and work towards re-connecting community members. We therefore see individual recovery from trauma and community social reconstruction as two parallel, non-linear and related processes: the individuals need to deal with disturbing posttraumatic symptoms and integrate their traumatic experiences and losses. 
Communities need to find ways to deal with painful collective history and overcome conflicting narratives about who-did-what-to-whom among various community groups. This is the only way the cycle of violence and victimisation can be interrupted. As individuals heal and communities reconstruct, both need to look for ways of integrating painful experiences in such a way that it contributes to the feeling of safety and self-worth of individuals, and stability and a sense of commonality for communities. In other words, the social context needs to be seen as safe enough to facilitate recovery. If there is determination to reduce violence and work on reinstating the social norms and values that promote tolerance, equality and sense of belonging, the environment will be conducive to healing and less distressing.

For these reasons we propose that recovery from collective trauma must be considered in the social context in which it was inflicted, among people who used to be close friends, colleagues and neighbours, where ethnic membership had not been an issue. Recovery should also be considered in respect of the existing context, which may include strong ethnic and other divisions, such as tensions among former refugees and the local population, and between those who became enormously rich during the war and those who became poor at the same time. The present forms the social context in which individual and collective trauma needs to heal, in which massive losses are to be grieved by people whose self-esteem and self-awareness have been damaged, who feel bitter because they feel that they have been let down and betrayed by friends, neighbours and fellow citizens in key life moments. No wonder that many report having an altered world-view and value system. Old social norms are gone and new ones are embraced by some but not all members of affected communities.

Our research in Vukovar has clearly shown this. ${ }^{8}$ For instance, the residents of the city agree that before 1991, relations among ethnic groups were very close, and that ethnicity of neighbours, colleagues at work or friends was of no relevance. This social norm has drastically changed and ethnic makeup became the key social marker in interpersonal relationships. The practice of Serbian and Croatian children attending separate schools has never been seen before. A high level of community division now affects sports, arts, and culture. Distrust, a feeling of personal insecurity, and almost exclusive connection to one's own ethnic group is emphasised by the fact that most of the public places (coffee shops, restaurants) are either 'Croatian' or 'Serbian'.

Members of an ethnic group do not look approvingly upon those who maintain even superficial contacts with the other group. Such change has definitely decreased the value of social capital in this community. Though other countries have been living with similar divisions rooted in social, economic, racial, or religious differences for decades, including dysfunctional parts of many major cities, such experience was unknown until 12 years ago in the communities we studied. This has also contributed to the 
profound disappointment and feelings of betrayal among the residents who have survived the war.

\section{The Perception of Justice}

A very important aspect of social context that can help traumatised individuals and community heal is the perception of justice and accountability for crimes committed during violence. The expectation is that individuals, who are guilty of committing violence, criminal acts or atrocities should be brought to justice. There are different ways that societies and the international community deal with this. One way is establishing truth commissions, as in South Africa, which collect testimonies from victims of organised violence and call on the perpetrators to admit their wrong-doing. In this setting the public airing of the grievances by large numbers of people and the admission of guilt by the perpetrators is seen as restorative.

Another approach is through a court of law. For example, the International Criminal Tribunal for Former Yugoslavia (ICTY) was established to investigate and prosecute war criminals in that region of Europe. It is expected that within the next few years the truth will become publicly known and the perpetrators punished though the court. If the truth about who did what in the past becomes known, then it is assumed that people who were terrorised can begin to heal. At the social and community level this suggests that a full accounting of crimes would facilitate reconciliation between former adversaries.

In addition to uncovering the truth, trials should attribute individual responsibility and guilt to perpetrators of atrocities and crimes against humanity. This will help locate the guilt on individuals that had been attributed to a whole ethnic group. All this should contribute to the psychological, moral and spiritual process of reconciliation and social reconstruction. If the perpetrators were exempt from punishment, then people would go on living with strong feelings of indignation, disappointment and bitterness because their suffering was not fully recognised and is seen to have no meaning; such impunity could seriously hinder the recovery and reconstruction processes.

Let us see how appropriate are such assumptions. A representative sample of 1,642 residents from three ethnic groups living in three ethnically divided cities in Croatia (Vukovar) and Bosnia and Herzegovina (Mostar and Prijedor), was surveyed for their attitudes the ICTY and war crimes. ${ }^{11}$ The group and study site influenced how the international criminal trials were viewed. Bosniaks, who are seen by themselves and by the international community as the principal victims of the wars, held positive views towards the tribunal, while the other groups held negative attitudes towards the ICTY. At the time of the survey, other groups felt that the members of their ethnic group were unfairly singled out for show trials, although two years 
later a further survey found that these attitudes changed, after the tribunal had indicted several high-ranking Bosnian military officers.

Given the generally negative perception of the tribunal, its role in contributing to reconciliation is evidently problematic. At the same time, the participants felt strongly that punishing war criminals from all sides was important for them personally and for social reconciliation. This apparently contradictory finding was explained by respondents who reported that they did not see the tribunal as contributing to reconciliation in their community. They felt that The Hague trials were too far removed from their reality, that the perpetrators who had terrorised them continued to live freely in their community and would never be tried in The Hague. The tribunal was felt irrelevant to delivering the justice which was of primary interest. At the same time there was concern that the national judicial system will need years before it is able to dispense fair and objective justice if high-ranking officers from their own national group were indicted for war-related crimes.

Exposure to war trauma by itself was not predictive of reconciliation, but its association with negative experience of the other ethnic group, feeling discriminated against and unsafe, predicted resistance to the reconciliation process.

\section{Social Reconstruction}

The key process conducive to recovery from individual and collective trauma and loss at the community level appears to be social reconstruction. This does not mean renewal of former social relationships as the people knew them. Too much pain had been inflicted among community members to aspire to rebuilding the same community as before. It is only possible to search for new forms of relationships, building different social structures and institutions, and enabling normal social functioning in a different context, thus meeting the needs and interests of the community. ${ }^{12}$

Social reconstruction can be defined as a process within a community which brings its damaged social functioning to a normal level of interpersonal and group relations and renews the social fabric of the affected community. ${ }^{11}$ Social reconstruction can only reach the level of social functioning that is acceptable to the majority of its members. Typically this is the level at which it is recognised that a common need cannot be accomplished through separate efforts, but that the members and groups need to work in agreement. Until the majority of residents become convinced that renewed co-operation is necessary, social reconstruction will remain at a low level.

Indeed, it is not easy for people to become functional neighbours and colleagues after they have contributed, whether actively or passively, to the disintegration of a community. It is predicted, from experience of the Israeli-Palestinian conflict, that members of a community will sooner or 
later identify overarching common goals, which cannot be achieved without mutually trusting relationships. ${ }^{13}$

But it cannot be ignored that the consequences of mass suffering and repression include very strong emotions. For example, a study conducted in 1999 on mental health, social functioning and attitudes of Kosovar Albanians, soon after the NATO bombing of Serbia, found that 90 per cent of women and 89 per cent of men expressed severe hatred toward the Serbs, while 43 per cent of women and 51 per cent of men expressed a strong wish and readiness to retaliate. The same study identified 17.1 per cent of the sample as meeting the criteria for PTSD. ${ }^{14}$

The process of social reconstruction as described here enhances the possibility for individuals and groups within a community to recognise each other and become recognised as important community members. Social reconstruction can be considered as rebuilding social structure and meeting the psychological and social needs of a society devastated by violence. It includes the return of refugees, demobilisation of soldiers and their reintegration into a community affected by the war, as well as training for productive employment. Furthermore, social reconstruction includes physical and psychological care and treatment of the victims, as well as raising awareness for respect of human rights. ${ }^{15}$

An ecological model of social reconstruction ${ }^{10}$ proposes that it consists of four elements: justice, democracy, economic progress, and reconciliation. The authors believe that reconciliation develops on an individual level and cannot be imposed. However, different interventions can pave the way for future reconciliation. On a short-term basis, co-existence can be sufficient to strengthen other elements of social reconstruction.

\section{Model of Community Social Reconstruction}

This paper proposes three parallel and simultaneous processes that compose community social reconstruction that can lead to outcomes at different levels (Figure 1). The starting assumption is that basic and existential needs are met to a certain degree.

One process refers to recovery from loss and exposure to violence. It includes raising awareness of the consequences of exposure to mass violence and social transition on the community, providing treatment to those who need it most. In community recovery and healing it is especially important to determine the fate of missing community members and to enable dignified burial rituals for all members. A central and at the same time a very sensitive issue is the recognition of the suffering and status of victims of collective violence. Traumatised people have a valid reason not to believe other people. The list of those who betrayed you in a key moment of life can be so long that someone is needed to confirm to you that you are not responsible for what happened and that you did not contribute. It is important that the victim gets this recognition from the community, and, if possible, from the perpetrators 
FIGURE 1

MODEL FOR FACILITATING COMMUNITY SOCLAL RECONSTRUCTION

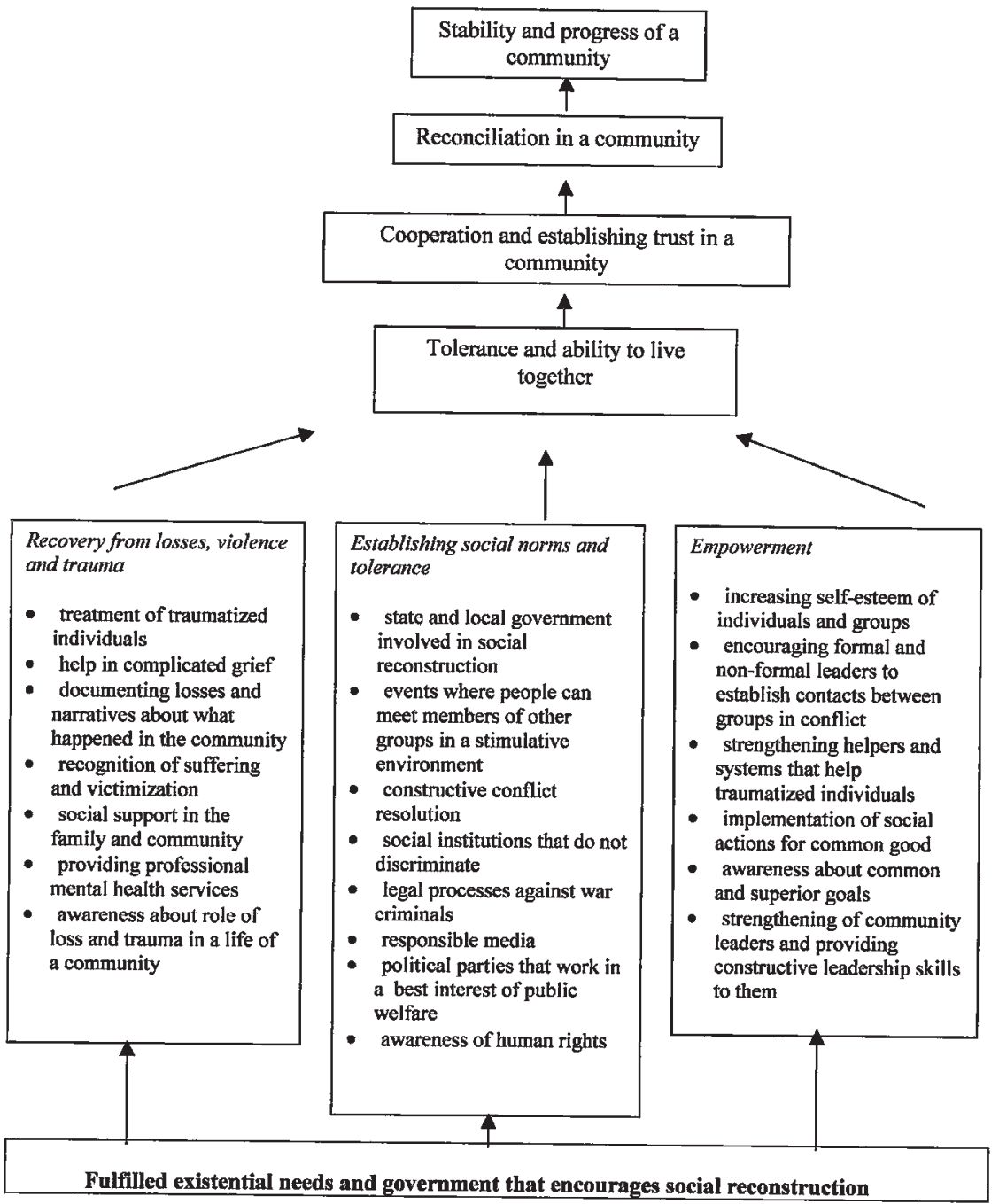

of the violence. Accepting the suffering of other people, and the possibility that someone from our group may have caused it, requires compassion and trust that simply does not exist between former enemies who are overwhelmed by their own pain, victimisation and suffering. ${ }^{16}$

The second parallel process includes actions that contribute to new social norms and tolerance. The role of the authorities is important, because the messages they send have a strong impact on attitudes and behaviour. Messages about whether it is or is not desirable to build contacts with 
members of other ethnic groups make people conform to what they think is the current behavioural norm. Other prominent members of a community can have the same function in the formation of norms. Thus, in building norms, it is important that there is simultaneous 'top down' and 'bottom up' action. ${ }^{17}$

To improve relations between conflicting groups, they need to maintain contact; which needs to be on an equal footing, frequent, and supported by people of authority. ${ }^{18}$ Both sides should share a common goal and while working towards it both sides should keep their independence. In this context, conflict management and associated skills need to be introduced in a community that has a poor history of managing differences in a constructive way. The relationship between integrating traumatic experiences and constructive conflict solving approaches is such that in order to develop constructive conflict management capacities, traumatised individuals, groups and communities must first integrate their traumatic experiences before they can develop the capacity for new approaches to conflict management. ${ }^{19}$

The third parallel process is empowering a variety of participants in creating community change. This process should help individuals feel like dignified human beings and increase their abilities to manage their own lives. Different systems of social support need to be strengthened, including careproviders and community leaders. Increasing feelings of self-esteem and selfefficiency is important to improve the quality of life of community members, and contribute to raising the feeling of safety and community belonging.

Both the role and vulnerability of care-providers in a community affected by mass violence are fairly specific.

First, since they belong to the community, they are also affected by communal and individual losses and are often traumatised. Prolonged high demands lead to burnout and a feeling of being overwhelmed and powerless. This requires provisions of specific assistance to the care-providers that meet their mental health needs, enabling them to continue providing quality service. $^{20}$

Second, care-providers face demands for services for which they may not have been properly trained, such as trauma treatment and grief work.

Third, to support prolonged demands, professional care-providers are responsible for recruiting non-professionals who must be trained and supported to reach out to others in need. Care-providers must thus be strengthened, retrained and supported as an important community resource.

These three processes are interdependent, developing simultaneously and non-linearly. Significant advancement can be achieved in the social reconstruction of a community in one period, although, in the next period, a delay or even regression can occur. In time, through a spontaneous decline in tension, and through conscious efforts, progress towards normalisation of the social functioning of a community can be expected. Planned, targeted 
and context-specific intervention can facilitate social reconstruction and decrease the time needed for more normal life in a community.

Social reconstruction in its early phase leads toward increased tolerance among the members of a community. In the next phase co-operation and building mutual trust, necessary for achieving overarching goals, may be expected. Social actions that involve members of different groups contribute to this phase. Trust should grow as a consequence of more frequent contacts in a favourable environment. It is important to reach an interpretation of past conflicts that is acceptable to all parties. It is difficult to build relationships when there are significantly different versions of events because they reflect different values. Trauma and losses should be recognised and respected in the entire community, regardless of group membership. Sincere sympathy for losses and suffering of others is a powerful bridge.

We observed in Vukovar that many Croats believe that Serbs who were able to remain living in Vukovar after the Croats were forced to flee were either passive or active accomplices to their trauma. ${ }^{8}$ They therefore expect from the Serbs a gesture of apology and remorse, and help in revealing the truth about missing family members. On the other hand, most of the Serbs that we interviewed emphasised that they personally harmed no one and cannot possible know the fate of missing Croat neighbours. They do not see any reason to show remorse, to apologise and much less to seek forgiveness.

Experience has shown that intervention programmes in which conflicting community groups discuss events of collective violence, learn about consequences of traumatisation and mechanisms of recovery, and share personal experiences, lead to positive change. ${ }^{21}$ Such changes are a key for social reconstruction, diminishing traumatic symptoms, increasing cooperation with the other groups and promoting acceptance of sympathy and apology when expressed. Good results in building connections among members of ethnic groups can be achieved through a programme including help in understanding psychological processes related to loss and trauma, recognising alternatives for constructive conflict resolution, sharing experiences of losses, and the planning of social action. ${ }^{22}$

In the next phase of social reconstruction, issues of reconciliation will surface. Meanings of the concept of reconciliation vary. It is posited that the key is socio-emotional reconciliation oriented toward overcoming conflictinduced feelings. A predominant feeling is the wish for retaliation, but when victims retaliate against perpetrators, they themselves become perpetrators, setting up a vicious circle of violence. Instead, a community can cope with its past if perpetrators (or their symbolic representatives) admit wrongdoing and ask for forgiveness, and victims (or their representatives) accept them. The past transforms the present and facilitates a better future. Trust is a precondition for both offering and accepting apology. The perpetrator must have confidence that the victim will respond with forgiveness and readiness to open a new chapter in the relationship. The victim must have confidence that the perpetrator who asks for forgiveness is sincere and not manipulative. 
Such basic trust is more likely when the conflict ends with shared agreement on who is the victim and who is the perpetrator of violence. In such situations, there is no need for proving who the victim is, and the perpetrator can expect that his confession of guilt will be returned with forgiveness. ${ }^{16}$

Reconciliation is problematic, however, when there are different interpretations of the roles of victims and perpetrators. A gradual building of trust between the two sides is necessary to reach key emotions, such as guilt and awareness of responsibility. Under very difficult circumstances, when there are no conditions for socio-emotional reconciliation, the process of instrumental reconciliation can be used, where, by making a series of steps around a task, one party needs and then helps the other party, and each has to co-operate with the former enemy in order to accomplish a shared goal.

\section{Conclusion}

The process of social reconstruction described in this paper accounts for both instrumental and socio-emotional forms of reconciliation. ${ }^{16}$ Mechanisms for trauma recovery, healing from violence and loss, building of social norms and tolerance, and strengthening of community resources, can lead to more demanding levels of social reconstruction, including reconciliation. Communities devastated by collective violence that invest in such a process should become more stable, with more social capital, and will prosper. Victims of trauma are more likely to become real survivors in such recovered communities.

\section{References}

1. Wilson JP. Trauma, transformation and bealing. New York: Brunner/Mazel, 1989.

2. Erikson KT. Disaster at Buffalo Creek. Loss of communality at Buffalo Creek Amer J Psych 1976; 133: 302-5.

3. Norris FH, Byrne CB, Diaz E, Kaniasty K. Psychosocial Resources in the Aftermath of Natural and Human-Caused Disasters: A Review of the Empirical Literature, with Implications for Intervention. White River Junction, VT: National Center for PTSD, 2002.

4. Ehrenreich J. Caring for Others, Caring for Yourself. New York: Mental Health Workers Without Borders, 2002.

5. Useem B. Breakdown theories of collective action. Ann Rev Sociol 1998; 24: 215-38.

6. Putnam RD. Making Democracy Work: Civic Tradition in Modern Italy. Princeton, NJ: Princeton University Press, 1993.

7. Putnam RD. Bowling Alone: the Collapse and Revival of American Community. New York: Simon \& Schuster, 2000.

8. Ajdukovic D, Corkalo D. Trust and betrayal in war: close interpersonal processes and implications for social reconstruction. In: Stover E, Weinstein H, eds. Rebuilding Communities: Justice in the Aftermath of Genocide and Ethnic Cleansing. Cambridge: Cambridge University Press, in press. 
9. Ignatieff M. The Warrior's Honor. Ethnic War and the Modern Conscience. New York: Henry Holt, 1998.

10. Fletcher LE, Weinstein $H$. Violence and social repair: Rethinking the contribution of justice to reconciliation. Human Rights Quarterly 2002; 24: 573-639.

11. Biro M, Ajdukovic D, Corkalo D, Djipa D, Milin P, Weinstein H. A survey of attitudes towards justice and social reconstruction in the former Yugoslavia. In: Stover E, Weinstein H, eds. Rebuilding Communities: Justice in the Aftermath of Genocide and Ethnic Cleansing. Cambridge: Cambridge University Press, in press.

12. Ajdukovic D. Socijalna rekonstrukcija zajednice [Community social reconstruction]. In: Ajdukovic D, ed. Socijalna Rekonstrukcija Zajednice: Psiboloski Procesi, Rjesavanje Sukoba i Socijalna Akcija [Community Social Reconstruction: Psychological Processes, Conflict Management and Social Action]. Zagreb: Society for Psychological Assistance, 2003:11-39.

13. Gal R. Social capital, citizenship behavior and service learning as strengthening forces for community reconstruction. Presentation to the 6 th International Conference for Health and Human Rights. Cavtat, Croatia, 24 June 2001.

14. Lopes Cardoso B, Kaiser R, Gotway CA, Agani F. Mental health, social functioning, and feelings of hatred and revenge among Kosovar Albanians one year after the war in Kosovo. J Traumatic Stress 2003; 16: 351-60.

15. Gutlove P. Conflict, conflict management and trauma recovery. Briefing manual for training workshop. Ohrid, Macedonia: Medical Network, 1999.

16. Nadler A. Post-resolution processes: Instrumental and socio-emotional routes to reconciliation. In: Salomon G, Nevo B, eds. Peace Education: the Concept, Principles, and Practices Around the World. New Jersey: Lawrence Erlbaum Associates, 2002: 127-41.

17. Corkalo D. Croatia: For peace education in new democracies. In: Salomon G, Nevo B, eds. Peace Education: the Concept, Principles, and Practices Around the World. New Jersey: Lawrence Erlbaum Associates, 2002: 177-86.

18. Allport G. The Nature of Prejudice. Reading, MA: Addison-Wesley, 1954.

19. Ajdukovic M, Sladovic FB. Razumijevanje sukoba [Understanding conflicts]. In: Ajdukovic D, ed. Socijalna Rekonstrukcija Zajednice: Psiholoski Procesi, Rjesavanje Sukoba i Socijalna Akcija [Community Social Reconstruction: Psychological Processes, Conflict Management and Social Action]. Zagreb: Society for Psychological Assistance, 2003: 195-210.

20. Ajdukovic D, Ajdukovic M, eds. Mental Health Care of Helpers. Zagreb: Society for Psychological Assistance, 2000.

21. Staub E. From healing past wounds to the development of inclusive caring: contents and processes of peace education. In: Salomon G, Nevo B, eds. Peace Education: The Concept, Principles, and Practices Around the World. New Jersey: Lawrence Erlbaum Associates, 2002: 73-86.

22. Ajdukovic D, Ajdukovic M, Corkalo D. Community Social Reconstruction, Conflict Management and Community Mental Health: Pilot Project. Zagreb: Society for Psychological Assistance, 2002, unpublished.

(Accepted 18 December 2003)

Dean Ajdukovic is a professor of psychology and director of the Postgraduate Psychology Program, University of Zagreb, Croatia, and president of the Society for Psychological Assistance (SPA), a regional mental health non-governmental organisation based in Zagreb. He has extensive experience in working with refugees and victims of organised violence and in social reconstruction and mental health interventions in communities affected by violence and social transition. He has 
published in five languages, lectured in centres of excellence in the US and Europe, and serves as consultant and trainer in several countries on psychosocial programme development and evaluation, refugee issues, children and youth violence, NGO strengthening, crisis interventions in the region of former Yugoslavia. He has been invited to work in other countries affected by upheaval. He is a member of the Council of the International Society for Health and Human Rights (ISHHR) and is president of the European Society for Traumatic Stress Studies (ESTSS).

Correspondence: Department of Psychology, University of Zagreb, Ivana Lucica 3, 10000 Zagreb, Croatia; e-mail: <dean.ajdukovic@ffzg.hr>. 